\title{
Crecimiento,
}

\section{inestabilidad y crisis de la convertibilidad en Argentina}

\section{José María Fanelli \\ Centro de Estudios de Estado \\ y Sociedad (CEDES), \\ Buenos Aires \\ josefan@cedes.org}

La economía argentina atraviesa actualmente el proceso recesivo más profundo y prolongado de la posguerra, panorama desolador que contrasta vivamente con su significativo crecimiento en 1991-1998. Aquí analizamos las dimensiones macroeconómicas de la crisis, que llevó a abandonar la convertibilidad. En primer lugar, identificamos algunas debilidades estructurales de la economía argentina, que son fuente de inestabilidad macroeconómica. En particular, estudiamos el papel del acceso imperfecto a los mercados internacionales de capital, la poca apertura, la falta de profundidad financiera y las rigideces nominales y de política; también analizamos el papel de los errores de expectativas y de la volatilidad. En segundo lugar, examinamos la secuencia de las perturbaciones (shocks) en 1998-1999, y aducimos que la simultaneidad de muchas de ellas agravó los efectos y que, bajo el régimen de convertibilidad, la economía no estaba preparada para encarar tales consecuencias. Por último, señalamos brevemente las políticas que el país debería aplicar para restablecer la estabilidad macroeconómica y financiera. 


\section{I}

\section{Introducción}

La economía argentina atraviesa por la más profunda y prolongada recesión que haya sufrido en la posguerra. El proceso se inició a fines de 1998, y a medida que pasó el tiempo y que fracasaron los sucesivos intentos de estabilización, los agentes económicos tomaron creciente conciencia de que el país entraba en el lóbrego reino de la depresión económica. Sus consecuencias están resultando devastadoras. En diciembre de 2001, el presidente democráticamente elegido fue obligado a renunciar y se abandonó el sistema de convertibilidad que se había adoptado en 1991. La tasa de crecimiento prevista para 2002 es de $-15 \%$ y la tasa de inflación va en aumento. Después de que la caja de conversión se reemplazó por un sistema de flotación, el peso ha perdido dos tercios de su valor frente al dólar. Casi la mitad de la población se encuentra por debajo de la línea de pobreza (en 1998 había un 28\% de pobres) y el país dejó de cumplir con el pago de la deuda.

Este panorama desolador contrasta marcada y vívidamente con el período 1991-1998, cuando la economía creció más de $41 \%$ y se vivió un importante proceso de privatizaciones destinadas a modernizar la infraestructura en el marco de un programa de reformas estructurales. En el período 1991-1998 se consideraba que Argentina era una de las economías emergentes más prósperas y la impresión favorable de los inversionistas permitió que el país colocara un volumen importante de bonos en los mercados de capital extranjeros. En 2001, los bonos argentinos representaron la cuarta parte del índice de J.P. Morgan para los bonos de mercados emergentes.

La diferencia entre los períodos 1991-1998 y 1999-2002 ha dado lugar a una curiosa situación que a la gente le cuesta comprender: en 2002, el PIB real

$\square$ Este trabajo fue preparado para la Conferencia "Financial Stability and Development in Emerging Economies", organizada por el Foro sobre deuda y desarrollo (FONDAP), en el marco de la Iniciativa sobre gobernabilidad financiera internacional, y auspiciada conjuntamente por el Ministerio de Relaciones Exteriores de los Países Bajos, el De Nederlansche Bank, el Centro Internacional de Investigaciones para el Desarrollo (CIID), la Comisión Económica para América Latina y el Caribe (CEPAL), el Fondo Monetario Internacional (FMI) y la Conferencia de las Naciones Unidas sobre Comercio y Desarrollo (UNCTAD). será inferior en 30\% al de 1998, pero la capacidad de producción es prácticamente la misma de fines de 1998, cuando comenzó la recesión. A menudo se escucha decir: "¡Cómo puede pasar esto, cuando no hemos tenido una guerra que destruya nuestra capacidad productiva!".

Dicho en otras palabras, si partiéramos de la base de que el PIB per cápita se define por el capital físico y humano acumulado por persona, la situación de Argentina no tendría explicación. Para comprenderla, entonces, tenemos que determinar por qué no se están utilizando plenamente valiosos recursos. Pero esto no es todo. En el caso de Argentina, también es fundamental explicar por qué el coeficiente de utilización de estos recursos es tan bajo y por qué la situación se ha prolongado tanto. Es decir, no se trata tan sólo de recesión sino de depresión. No podemos pasar por alto el hecho de que la tasa de desempleo se está aproximando a la cuarta parte de la fuerza laboral y que, entre el tercer trimestre de 1998 y el segundo de 2002, la serie trimestral del PIB no registra crecimiento en trece trimestres.

En este artículo sostendremos que la tasa tan baja de utilización de los recursos que se registra actualmente obedece a que al abandonarse la caja de conversión, se desmoronó la estructura institucional y contractual de la economía. En tales circunstancias resulta muy difícil definir los derechos de propiedad en forma adecuada y precisa. De ahí que parte importante de los agentes económicos carezca de incentivo para sacarle el máximo de provecho a los recursos disponibles.

Tres factores son esenciales para comprender por qué en las instituciones económicas la desorganización fue tan generalizada. El primero de ellos se relaciona con las características y la secuencia en el tiempo de las perturbaciones (shocks) que sacudieron a la economía en 1998-1999. A partir de 1998, Argentina sufrió una serie de conmociones que afectaron seriamente su competitividad y su situación financiera. Entre ellas cabe mencionar la caída de los precios de las exportaciones y el deterioro de la relación de intercambio, las restricciones de los mercados de crédito externos, la apreciación del dólar y la devaluación del real en Brasil. Además, el ciclo político provocó una perturbación fiscal. El segundo factor lo constituyen las especiales características de los sistemas fiscal, monetario y fi- 
nanciero argentinos, que contribuyeron a amplificar los efectos de las perturbaciones. En el sistema de convertibilidad, los mecanismos anticíclicos eran extremadamente limitados. Los precios y salarios no eran lo suficientemente flexibles; el sistema fiscal era rígido (particularmente las relaciones entre el Gobierno Federal y las provincias) y estaba sujeto a influencias políticas. El tercer factor se relaciona con el régimen de caja de conversión. Este se había estado aplicando durante más de diez años y tras salir airoso del efecto tequila en 1995, había logrado inspirar confianza. De ahí que las relaciones contractuales privadas tuvieran que adaptarse en gran medida a sus normas, especialmente en los contratos en dólares. La dolarización de los instrumentos financieros acarreó mayores limitaciones, al punto que la depreciación real aumentaría la vulnerabilidad financiera de las empresas y tornaría más dudosa la situación financiera de los bancos.

Pero aunque lográramos explicar por qué razón y de qué manera la convertibilidad y las perturbaciones que hubo culminaron en la crisis actual, cabría preguntar por qué Argentina adoptó un sistema de esa naturaleza y por qué el país estuvo tan expuesto a perturbaciones como las ocurridas. Estas preguntas nos llevan a formularnos muchas otras: ¿a qué se debe que Argentina haya optado por un sistema tan rígido como el de caja de conversión?, ¿por qué se dolarizaron los contratos?, ¿por qué los inversionistas extranjeros fueron tan desatinados como para comprar bonos de largo plazo de un país que caería en mora pocos años después?, ¿por qué fue tan comprensivo el FMI con las políticas del país y le prestó su apoyo durante la vigencia de la convertibilidad? Para responder a estas preguntas es preciso examinar algunas características específicas de la economía argentina que contribuyeron de manera decisiva a generar los desequilibrios macroeconómicos y la dinámica de ajuste que se observan generalmente. A nuestro juicio, son fundamentales las que se exponen a continuación.

Primero, en Argentina al parecer se cometen "grandes" errores en las previsiones con más frecuencia que en países similares. A manera de ejemplo, citamos algunos errores relacionados con la crisis actual que fueron cometidos por los agentes supuestamente mejor informados: los bonos argentinos constituían la cuarta parte del índice de J.P. Morgan y el país cayó en mora en el pago de sus obligaciones; parte importante de la cartera de créditos de los bancos de propiedad extranjera se asignó a productores de bienes no transables, que después de la devaluación no pudieron cumplir sus obligaciones; una proporción significati- va de la inversión extranjera directa en el sector de bienes transables resultó ser excesiva; las empresas que fueron privatizadas suscribieron contratos que no podrían cumplir si se abandonaba la convertibilidad; y el FMI prestó apoyo a programas de estabilización cuyas metas eran prácticamente imposibles de alcanzar.

Segundo, la acción recíproca entre la estructura económica argentina y las perturbaciones a que está expuesto el país a menudo da lugar a efectos "perversos". Dicho más concretamente, esta acción recíproca se traduce en procesos estocásticos de generación de datos que son inestables (esto es, están sujetos a cambios estructurales frecuentes e inesperados) y son volátiles. Esto significa que las posibilidades de que las previsiones sean inconsistentes y de que se cometan "grandes errores" no surgen porque los agentes sean poco sofisticados, sino por la complejidad e inestabilidad inherentes a los procesos que los agentes deben "modelar" para pronosticar cómo evolucionarán las variables que interesan, ${ }^{1}$ todo lo cual influye en su comportamiento económico. Entre los hechos más importantes para entender la experiencia argentina cabe mencionar la menor duración de los contratos y la existencia de mercados financieros incompletos.

Tercero, la estructura económica presenta algunos rasgos que contribuyen a amplificar las consecuencias de las perturbaciones. Destacaremos tres rasgos: el tipo de integración internacional, las rigideces que afectan a las variables nominales y de política, y el insuficiente desarrollo financiero. A decir verdad, en las actuales circunstancias, la falta de factores que aminoren los efectos de las fluctuaciones es particularmente manifiesta. La crisis financiera, la caída del ingreso nacional y la incertidumbre política dieron lugar a vigorosas fuerzas desestabilizadoras. Sin más mecanismo compensatorio que el mercado, la economía se encuentra actualmente en estado de depresión.

Este artículo examina los aspectos macroeconómicos de la crisis argentina. Lo expresado más arriba revela la importancia de las características estructurales. Por lo tanto, en la sección II se examina el problema de los cambios estructurales y la elevada volatilidad, así como su relación con los errores en las previsiones y con las características de los contratos que se suscribieron en Argentina. En la sección III se estudian las perturbaciones de 1998-1999 y su interacción con la estructura económica del país, y se hace hincapié en el

\footnotetext{
${ }^{1}$ Heymann, Kaufman y Sanguinetti (2001) y Fanelli y Heymann (2002) analizan estas cuestiones en el contexto de los países latinoamericanos.
} 
papel que desempeñan la integración internacional, las rigideces nominales y de política y los efectos finan- cieros. En la sección IV se formulan algunas observaciones finales.

\section{II}

\section{Cambios estructurales, volatilidad}

\section{y macroeconomía}

La literatura relativa a las fluctuaciones macroeconómicas que se producen en los países en desarrollo muestra de manera creciente que ellas tienen características distintas de las observadas en los países de la OCDE (Agénor, McDermott y Prasad, 2000; Easterly, Islam y Stiglitz, 2000; Fanelli, 2000). Esto a menudo se atribuye a diferencias en materia de estructura económica. Uno de los aspectos que se destaca reiteradamente es la mayor volatilidad de las series macroeconómicas correspondientes a las economías de menor desarrollo. Un segundo aspecto es la incidencia de las reformas estructurales. En el caso de Argentina, estimamos que ambos factores son importantes. A nuestro juicio, es la presencia misma de una elevada volatilidad y de cambios estructurales lo que complica el proceso de formación de expectativas y hace inestable a la macroeconomía.

Es bien sabido, por cierto, que las fluctuaciones de las variables agregadas siempre pueden interpretarse como resultado de planes elegidos deliberadamente por agentes que tienen expectativas acertadas. De acuerdo con esta hipótesis, la actual recesión argentina sería un fenómeno de "equilibrio". Pero, contrariamente a este punto de vista, sugerimos que en el caso de Argentina los agentes cometieron errores importantes y que, como consecuencia de ello, están revisando a fondo sus previsiones relativas al ingreso permanente y se han embarcado en un proceso general de reformulación de los contratos. Hay dos hechos específicos que hablan a favor de un enfoque de "desequilibrio". Primero, parece difícil explicar una recesión tan profunda y prolongada como la actual sin introducir la cuestión de expectativas no satisfechas. Hay que tener en cuenta, además, que en Argentina no sólo se ha producido una fuerte caída del nivel de actividad, sino también una situación que ordinariamente llamamos de "crisis", esto es, una situación en que un gran número de agentes no cumplen sus obligaciones contractuales. Muchas empresas e intermediarios financieros enfrentan la quie- bra y, por ende, las instituciones básicas tanto fiscales como financieras e incluso políticas son objeto de fuertes presiones. Segundo, la diferencia entre una "crisis" y el incumplimiento aislado de un contrato radica en que la primera entraña el peligro de incumplimiento general de los contratos y de atropello del derecho de propiedad. Por lo tanto, para descartar los errores por hipótesis tendríamos que afirmar que, al adoptar las decisiones, los agentes ya han previsto e internalizado los enormes costos de transacción en que incurrirían si se produjera la situación "mala" (esto es, un estado de crisis caracterizado por la redefinición generalizada de los contratos y de los derechos de propiedad). Partiríamos de la base de que, al aceptar las condiciones de un contrato, el sector privado ha internalizado totalmente los costos de los efectos externos negativos que una crisis sistémica generaría.

Uno de los aspectos que suele destacarse menos y que es importante para comprender la experiencia argentina es que la inestabilidad macroeconómica y los grandes errores de expectativas también pueden producir "mutaciones" de la estructura económica. Esto puede suceder porque los agentes económicos tienen en cuenta que viven en una economía inestable y modifican su comportamiento. Un ejemplo típico de esta clase de fenómeno es el hecho de que los contratos que se pactan en condiciones de alta incertidumbre son de menor duración, lo que puede tener consecuencias permanentes en la economía. Puede afectar a la profundidad financiera y, por esta vía, a la inversión y la gestión del riesgo. De esta manera, la inestabilidad en sí puede generar trastornos estructurales. De ahí que haya que considerar la interacción de los desequilibrios, la dinámica macroeconómica y la estructura microeconómica (Fanelli, 2000).

En la presente sección examinamos más detenidamente estas cuestiones y ofrecemos evidencia empírica, a nuestro juicio importante, para comprender la crisis argentina actual. Antes de entrar de lleno en el 
análisis de los datos, en el apartado que sigue hacemos una breve digresión referida a la relación entre expectativas, cambio estructural y volatilidad, que será útil para hacer más clara la interpretación de los datos de serie de tiempo correspondientes a Argentina.

\section{La volatilidad, los cambios estructurales y las expectativas}

Como lo indican los datos que ofrecemos más adelante, no hay duda alguna de que la economía argentina es extremadamente inestable. Dos características típicas de la inestabilidad son los cambios estructurales y la volatilidad. En relación con la volatilidad, la varianza de los procesos estocásticos no sólo tiende a ser grande sino que es variable (existe heterocedasticidad). Así, en el caso de Argentina, usualmente se alternan períodos de turbulencia y de calma, lo que sugiere la conveniencia de asumir una varianza condicional variable para modelar los procesos estocásticos. Nótese que una varianza condicional muy cambiante tiene consecuencias económicas, ya que la varianza condicional influye en la prima de riesgo (Enders, 1995). ${ }^{2}$

En el caso de Argentina, los cambios estructurales son importantes porque los "parámetros profundos" que definen la estructura económica ${ }^{3}$ tienden a cambiar inesperadamente y con mayor frecuencia que, por ejemplo, en los países de la Organización de Cooperación y Desarrollo Económicos (OCDE). Esto influye en la estabilidad porque, por una parte, si el cambio estructural es "único", no puede conocerse con antelación (en otras palabras, los agentes no conocen de antemano la distribución de probabilidades de estas clases de perturbaciones). Por la otra, si se produce un cambio importante, los agentes tienen que aprender a

\footnotetext{
${ }^{2}$ Los períodos de turbulencias y tranquilidad también pueden asociarse con una varianza no condicionada que depende del tiempo, esto es, con variaciones de la volatilidad que son permanentes en lugar de transitorias. Sin embargo, no conozco estudios que se refieran al tema en Argentina.

${ }^{3} \mathrm{Al}$ decir estructura económica, nos referimos al conjunto de variables y parámetros exógenos que representan el comportamiento de los agentes, el régimen de política y la distribución de las probabilidades que rigen los procesos estocásticos. Por lo tanto, si suponemos que la estructura económica puede representarse en función de la forma reducida del modelo (esto es, en función de variables y parámetros exógenos), lo que queremos decir es que los parámetros y las variables que se introducen en la forma reducida varían inesperadamente, siguiendo un patrón estocástico que el agente no puede desentrañar adecuadamente cuando se forman las expectativas. Naturalmente, los agentes pueden aprender, pero entretanto sus errores de expectativas serán importantes para el equilibrio macroeconómico.
}

conocer cómo funciona la economía en las nuevas circunstancias. Esto origina "incertidumbre respecto del modelo" y dificulta la formación de expectativas. El fenómeno tiende a generar incertidumbre "pura", porque el agente sabe que puede ocurrir "algo", pero no puede calcular las probabilidades ni describir con exactitud hasta qué punto el suceso afectará a la economía.

Obviamente, no todos los cambios estructurales tienen iguales posibilidades de provocar inestabilidad y problemas de aprendizaje. Si los agentes económicos prevén cabalmente el cambio, lo incluirán en el conjunto de información pertinente y lo tendrán presente cuando negocien las condiciones de un contrato. Lo más probable es que no sea el tipo de cambio estructural que genera inestabilidad y grandes errores de expectativas. Las alteraciones estructurales que originan inestabilidad generalmente van unidas a la ocurrencia de acontecimientos que no sólo tienen efectos permanentes en la economía, sino que, además, son "únicos" o "realmente nuevos". Si hasta a los agentes mejor informados les cuesta prever la perturbación y/o determinar sus consecuencias, es razonable esperar que ello afecte al comportamiento.

Es probable que de esta clase de acontecimientos surjan dos consecuencias observables. La primera es que la serie correspondiente debería presentar saltos aislados y no acusar tendencia a volver al nivel anterior a la alteración. Por ejemplo, considérese el caso de un cambio único permanente de la media de una secuencia que sin ese cambio sería estacionaria, o el caso de una sola "pulsación" que influya de manera permanente en el valor medio de una serie de raíz unitaria. Segundo, las fluctuaciones del nivel de volatilidad deben observarse cerca de los puntos en que el proceso da un salto aislado importante. Esto derivaría de cambios en la incidencia de los errores de pronóstico. Inmediatamente después de producida la perturbación, se comprobará que los planes fueron errados y, en general, inconsistentes unos con otros. Pero a medida que el conocimiento va reduciendo los errores de expectativas y los contratos se van renegociando, la varianza condicionada media debería tender, después de un tiempo, hacia la varianza no condicionada. Asimismo, es posible que se produzcan cambios permanentes en el valor de esta última, lo que sucedería, por ejemplo, si un programa de estabilización lograra reducir la variabilidad de los precios relativos mediante una desinflación de la economía. Es un hecho comprobado que la inflación se relaciona directamente con la variabilidad de los precios relativos.

Vale la pena destacar algunos fenómenos económicos específicos que se asocian a los cambios 
estructurales y la volatilidad, ya que ellos intervienen en nuestro análisis de Argentina. Primero, como lo subrayan Heymann, Kaufman y Sanguinetti (2001), después que ocurre una perturbación positiva o negativa que produce un cambio, a los agentes les resultará muy difícil determinar cuál es la "verdadera" tendencia de crecimiento de la economía y, en consecuencia, decidir cuál debería ser su nivel de gasto y de exposisión al riesgo financiero. Si los agentes se equivocan, la asignación de los recursos en el tiempo y de acuerdo con el estado de la naturaleza no será eficiente y redundará en una inconsistencia global de los planes.

Segundo, en la medida en que el valor real de los activos utilizados como garantía dependa del estado de la economía, el cambio de percepción acerca de las perspectivas futuras influirá en las condiciones que ofrezcan los mercados de crédito. Asimismo, si varía el grado de volatilidad, tanto la percepción del riesgo como el precio de los activos cambiarán: serán inversamente proporcionales a la inestabilidad condicional. Esto es particularmente importante si los mercados son incompletos. En estas condiciones, es difícil eliminar el riesgo a través de su diversificación y las posibilidades de cubrirse disminuyen. Por lo tanto, si los productores tienen aversión al riesgo, la variabilidad condicional de los precios afectará la oferta de productos y es posible que los productores reduzcan su exposición al riesgo retirándose del mercado en períodos en que éste es considerable. En términos globales, si es difícil aminorar el riesgo mediante su diversificación y cubrirse en los mercados financieros internacionales, una mayor volatilidad se traduce en una prima de riesgo más alta, lo que a su vez afecta la asignación de los recursos y, por ende, el crecimiento.

Tercero, en condiciones de volatilidad y cambios estructurales tal vez no pueda decirse que lo que pasó, pasado está. Las expectativas del pasado influirán en el presente en la medida en que estén incorporadas en los contratos suscritos en el pasado y que aún se encuentren en vigor. Si las expectativas estuvieran "muy" equivocadas, es posible que alguna de las partes no esté en condiciones de cumplir el contrato y que haya que modificar sus términos. Por lo tanto, cuando los agentes tomen decisiones tendrán en cuenta que la probabilidad de que estén "muy" equivocados no es igual a cero y, además, que las percepciones del futuro que tengan otros agentes pueden cambiar en forma repentina. Siendo iguales las demás condiciones, cabría esperar que, a mayor incertidumbre acerca de la "verdadera" forma de la distribución multivariada que da origen a la información pertinente, menor sería la duración de los contratos. En las economías sujetas a in- certidumbre pura, deberíamos encontrar que, en promedio, los contratos son más cortos cuando los agentes tratan de protegerse de "saltos malos" únicos en la tendencia estocástica de la economía. También deberíamos encontrar situaciones de colapso sistémico, en que los cambios inesperados en la tendencia estocástica de la economía y, por lo tanto, en los flujos monetarios y las garantías, se traducen en el incumplimiento general de los contratos.

Cuarto, en condiciones de incertidumbre, la liquidez tendrá especial valor debido a que la recontratación es costosa y mientras mayor sea la probabilidad de que las expectativas hayan sido erradas, más necesario será volver a contratar. A nuestro juicio, ésta es una de las razones por las cuales, en las condiciones de gran incertidumbre que suelen preceder a cambios permanentes de política - como el inicio de un programa de estabilización cuyas consecuencias son difíciles de determinar-, los agentes perciben como más conveniente adoptar posturas de "veamos qué pasa" o "seamos flexibles y tengamos liquidez". En la medida en que la opción de esperar tenga mayor valor, el aumento de la preferencia por la liquidez será la norma.

\section{Las tendencias y la inestabilidad macroeco- nómica}

¿Muestran las series de tiempo correspondientes a Argentina la volatilidad y los cambios estructurales que deberían estar asociados al tipo de inestabilidad que hemos examinado? En otras palabras, ¿hay saltos repentinos en la evolución del crecimiento y explosiones de volatilidad? ¿Afecta la inestabilidad macroeconómica a la duración media de los contratos? ¿Hay interacción de las condiciones del crédito, las perturbaciones y las fluctuaciones globales? ¿Se observan cambios repentinos en las preferencia por liquidez?

El gráfico 1 muestra la evolución del PIB per cápita en Argentina en los últimos cincuenta años y la tendencia Hodrick-Preston correspondiente. Como puede verse, la tasa media de crecimiento es baja y la tendencia acusa variaciones de importancia que van unidas a crisis macroeconómicas y financieras y/o a cambios de régimen (1975-1976; 1980-1981; 1988-1989; 1991; 1999-2001). Asimismo, son frecuentes los "acontecimientos significativos" que producen marcadas rupturas en la evolución del nivel de actividad y saltos discontinuos de la tasa de crecimiento. Si se compara esta serie de tiempo con la de un país típico de la Organización de Cooperación y Desarrollo Económi$\cos (\mathrm{OCDE})$, veremos que en Argentina hay más altiba- 
GRAFICO 1

Argentina: Producto interno bruto real per cápita

(Pesos constantes de 2000)

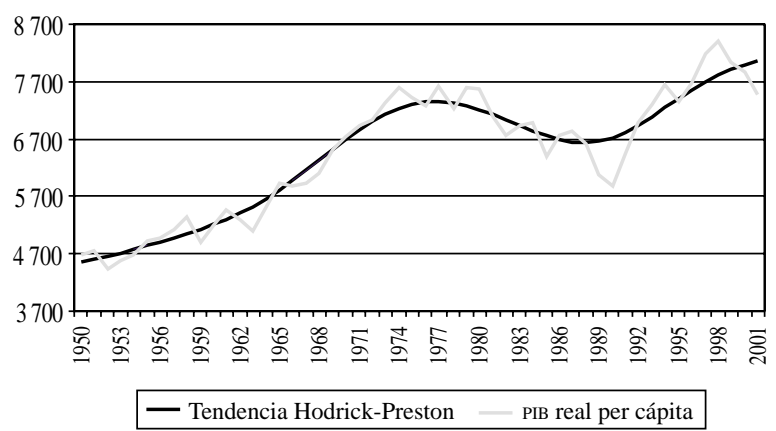

jos y que es más frecuente que se produzcan acontecimientos significativos. En rigor, este hecho estilizado no es exclusivo de Argentina. Easterly, Islam y Stiglitz (2000) muestran que es mucho más probable que haya crecimiento negativo del producto por habitante en los países que no pertenecen a la OCDE que en los países industrializados. Sostienen que los primeros exhiben crecimiento negativo un $22 \%$ del tiempo, mientras que en los países de la OCDE la cifra es de poco más de $9 \%$. La probabilidad de crecimiento negativo en Argentina (36\%) es mucho más alta que en el promedio de los países en desarrollo.

Cabe destacar que la crisis de 1975 fue un punto de quiebre decisivo en lo que se refiere a la inestabilidad y al régimen económico. A partir de ese año Argentina abandonó definitivamente su estrategia más bien infructuosa de sustitución de importaciones y su aproximación a la política económica se hizo mucho más favorable al mercado. El grado de volatilidad fue muy diferente antes y después de ese punto (cuadro 1). Entre 1950 y 1974, la probabilidad de crecimiento negativo en Argentina coincidió aproximadamente con la observada en el conjunto de los países en desarrollo (21\%). Sin embargo, en el período 1975-2001 esta probabilidad se elevó a $52 \%$, lo que quiere decir que el PIB per cápita cayó más veces que las que aumentó. Por lo tanto, la tasa media de crecimiento del PIB per cápita fue muy inferior, mientras que el coeficiente de variación se elevó marcadamente. Asimismo, aun cuando el segundo período incluye los diez años en que rigió el sistema de convertibilidad, durante los cuales la inflación fue muy baja, tanto la tasa de inflación como la variación de los precios relativos fueron significativamente más altas. Sin embargo, en ambos períodos hubo grandes descensos y acentuadas aceleraciones de la inflación.
Debido a la abundancia de saltos y de hechos significativos, se ha dicho que este comportamiento dinámico es una modalidad de crecimiento de "para y sigue". Una de sus características es que todas las cifras macroeconómicas globales tienden a acusar una acentuada variabilidad. La volatilidad de las inversiones, el consumo y el crecimiento del PIB en Argentina es elevada incluso si se la compara con la de los países en desarrollo. El cuadro 2 muestra la volatilidad de estas variables en Argentina y en países latinoamericanos similares. ${ }^{4}$

Nótese que el crecimiento del consumo es más volátil que el del PIB. Esto sugiere que en los mercados de capital hay fallas importantes que dificultan la nivelación del consumo e indica que los costos por concepto de bienestar inducidos por fallas de los mercados financieros pueden ser significativos. También revela que Argentina tiene severas limitaciones para diversificar el riesgo nacional.

En la economía argentina también es posible identificar períodos de calma y de turbulencia. La presencia de explosiones de volatilidad es particularmente manifiesta en las series de precios relativos. Para ilustrar este punto, en el gráfico 2 se muestra la evolución del tipo de cambio real en los últimos 25 años. ${ }^{5}$ Nótese en primer término la relación entre los quiebres y la volatilidad: los grandes saltos hacia arriba del tipo de cambio real van seguidos de variaciones en el nivel de volatilidad. En un análisis más sistemático realizado con modelos ARCH y GARCH, ${ }^{6}$ Fanelli y Rozada

GRAFICO 2
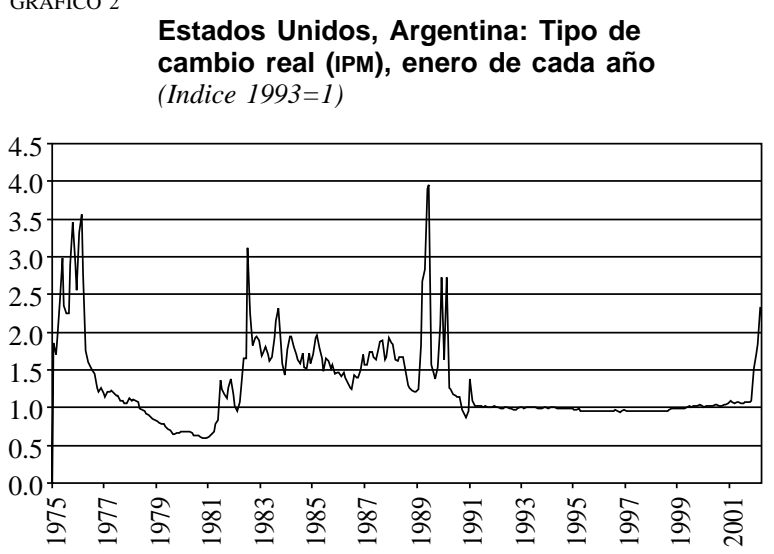

4 Véase más sobre este tema en BID (1995).

${ }^{5}$ El tipo de cambio real se define como el índice de precios mayoristas de los Estados Unidos multiplicado por el tipo de cambio nominal sobre el índice de precios mayoristas de Argentina.

6 ARCH= Autoregressive Conditional Heteroskedasticity. GARCH= Generalized Autoregressive Conditional Heteroskedasticity. 
Argentina: Inflación e inestabilidad del crecimiento entre 1950 y 2000

\begin{tabular}{lrr}
\hline & $1950-1974$ & $1975-2000$ \\
\hline Tasa media de inflación (IPC) ${ }^{\mathrm{a}}(\%)$ & 24.3 & 94.7 \\
Coeficiente de variación de los precios relativos (IPM/IPC) & 60.9 & 0.34 \\
Tasa media de crecimiento del PIB per cápita (\%) & 0.08 & 0.13 \\
Probabilidad de crecimiento negativo (\%) & 2.02 & 52 \\
Coeficiente de variación de la tasa de crecimiento & 21 & 36 \\
del producto interno bruto per cápita & 2.08 & 37.27 \\
\hline
\end{tabular}

Fuente: Datos de CEPAL (1998 y 2002).

a IPC: Indice de precios al consumidor. ${ }^{b}$ IPM: Indice de precios mayoristas.

CUADRO 2

\section{Argentina: Volatilidad de las cifras macroeconómicas globales}

\begin{tabular}{lccc}
\hline País & \multicolumn{3}{c}{ Coeficiente de variación } \\
\cline { 2 - 4 } & $\begin{array}{c}\text { Crecimiento de la } \\
\text { inversión }\end{array}$ & $\begin{array}{c}\text { Crecimiento } \\
\text { del consumo }\end{array}$ & $\begin{array}{c}\text { Crecimiento } \\
\text { del PIB }\end{array}$ \\
\hline Argentina & 7.1 & 2.4 & 1.8 \\
Brasil & 2.4 & 0.9 & 0.9 \\
Chile & 2.6 & 2.3 & 1.1 \\
México & 3.5 & 1.0 & 0.9 \\
\hline
\end{tabular}

Fuente: Datos de Banco Mundial (1999).

(1998) mostraron que la varianza del tipo de cambio real presenta heterocedasticidad condicional. En otras palabras, la varianza condicional depende del conocimiento que se haya tenido en el pasado del proceso de error; de ahí que los "grandes" errores den lugar a "grandes" varianzas en las observaciones próximas. Otra característica es que los saltos del tipo de cambio real y las variaciones extremas de la volatilidad generalmente van unidos a cambios de régimen. Entre esos saltos, los más marcados tienden a coincidir con el final abrupto de algún régimen de paridad fija, en el contexto de tras crisis de balanza de pagos con fuga de capitales. Estos cambios de régimen (en 1975, 1981, 1989 y 2001) estuvieron vinculados con grandes oscilaciones de la política económica. Los dos períodos de menor volatilidad de la serie corresponden a sistemas en que se utilizó el tipo de cambio como soporte nominal: el período de la "tablita", de 1978-1981, y la década de convertibilidad (1991-2001). A nuestro juicio, esto demuestra que el sistema monetario y cambiario puede no ser neutro, es decir, que los distintos sistemas influirán de diversa manera sobre la evolución de la economía (Fanelli y Heymann, 2002).

Los estudios relativos al Mercosur también sugieren la importancia de las mudanzas de régimen cambiario. En el decenio de 1990, la transmisión de los impulsos macroeconómicos entre los países del Mercosur adquirió mayor importancia a medida que aumentó el volumen de comercio, a partir de niveles bastante bajos. Así, para Argentina el intercambio real bilateral con Brasil pasó a ser una variable cada vez más significativa. Chudnovsky y Fanelli (2001) examinaron los atributos de la serie, utilizando modelos GARCH, y comprobaron que la variable era significativamente volátil y que los cambios de régimen, como el inicio de la convertibilidad en Argentina en 1991, y la flotación (acompañada de devaluación) monetaria en Brasil en 1999, tuvieron consecuencias importantes.

La inestabilidad del tipo de cambio real se suma a las variaciones del PIB real para determinar amplias fluctuaciones del valor en dólares del PIB. El coeficiente de variación del PIB real argentino en dólares de valor constante casi duplica el correspondiente al PIB real en pesos de valor constante $(0.66$ y 0.36 , respectivamente). Sin embargo, los sectores de bienes transables y no transables contribuyen de manera muy diferente a la varianza. La fluctuación del valor en dólares del segundo es muy superior. Los gráficos 3 y 4 muestran la evolución de la producción total, de los bienes transables y de los no transables, en dólares y pesos de valor constante, respectivamente. Obsérvese la diferencia apreciable y cada vez mayor entre el valor en dólares de los bienes transables y el de los no transables en el período de convertibilidad (1991-2000) y también durante la aplicación de la "tablita" (1978-1981). Al parecer, bajo regímenes que fijan o pautan la evolución del tipo de cambio nominal tiende a inflarse el valor en dólares de los bienes no transables. A su vez, la apreciación del valor en dólares de estos bienes tiende a desaparecer junto con los regímenes de paridad fijada. Esto puede ser fuente de fragilidad financiera si, bajo un sistema de paridad fija, las empresas utilizan activos productivos no transables con valores inflados 
GRAFICO 3

Argentina: PIB bienes transables y no transables

(Millones de dólares constantes de 2000)

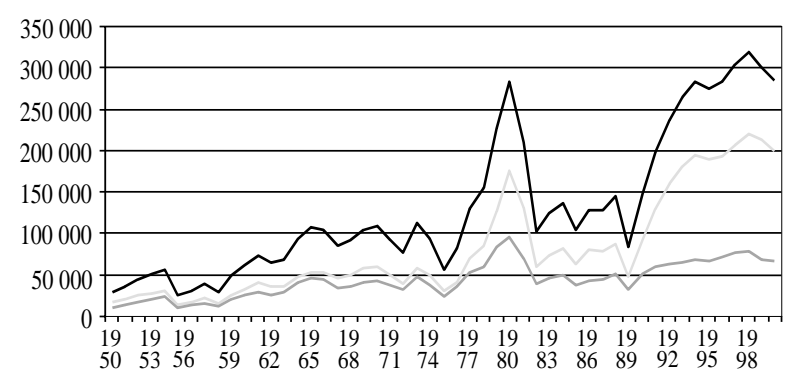

- PIB - Bienes transables - Bienes no transables

GRAFICO 4

Argentina: PIB bienes transables

y no transables

(Millones de pesos constantes de 2000)

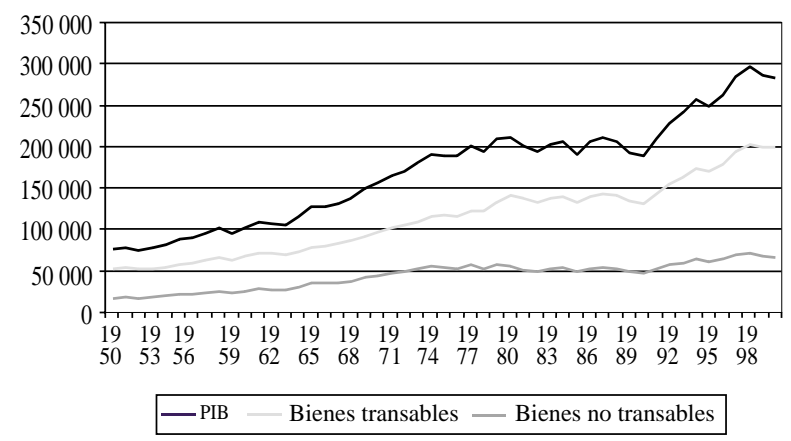

como garantía para obtener crédito dolarizado en el sistema bancario nacional o en los mercados de crédito extranjeros.

Ya hemos destacado la mayor inestabilidad macroeconómica del período comprendido entre 1975 y 2001. El gráfico 3 muestra claramente que la fluctuación del valor en dólares del PIB y, en especial, de los bienes no transables es mayor en ese período. Es posible que esto también haya influido en la reiteración de las crisis financieras durante los últimos 25 años. Desde luego, a diferencia del período 1950-1975, en que los flujos de capital eran poco significativos y no se conocía la dolarización, los movimientos de capital se tornaron cada vez más importantes a partir de fines del decenio de 1970, cuando Argentina comenzó a abrir su cuenta de capital. Al mismo tiempo, surgió una persistente tendencia a expresar en dólares los instrumentos financieros nacionales. Como resultado, las empresas que producían artículos cuyo valor en dólares era muy fluctuante vieron desaparecer gradual- mente los instrumentos de crédito expresados en pesos. Con ello no queremos insinuar que entre la liberalización de la cuenta de capital, la dolarización y la inestabilidad haya una simple relación de causa a efecto. Más bien, nos interesa hacer hincapié en las interacciones perversas que pueden darse en este contexto.

Fanelli y Heymann (2002) subrayan que en una economía fuertemente dolarizada como la argentina, esto puede afectar seriamente la estabilidad financiera. La dificultad para determinar cuáles son los niveles de gasto sostenibles puede deteriorar la calidad de las decisiones (Heymann, Kaufman y Sanguinetti, 2001): cuando la tendencia es oscilante, en algún momento los agentes pueden enterarse de que, en realidad, sus gastos han sido extremadamente procíclicos y que han estado gastando más que lo que ganan. No es posible soslayar la necesidad de identificar los gastos permanentes cuando se adoptan decisiones relacionadas con la producción, el gasto y la tenencia de activos. En la Argentina pos-1998, la comprobación de que su patrimonio había sido sobrevalorado desembocó en un ajuste extremadamente traumático, que culminó en la crisis actual. El sistema de contratos financieros mayoritariamente expresados en dólares que se desarrolló bajo el régimen de convertibilidad monetaria fue sumamente vulnerable a las fluctuaciones del valor en dólares de los ingresos. Esto condujo al incumplimiento de los contratos, lo que de por sí fue fuente de desorden económico, al punto que desencadenó una crisis financiera. Además, debemos tener presente que, para un país endeudado en dólares, el valor en dólares de su PIB es importante porque se utiliza para evaluar la capacidad de pago del país, generalmente conforme a la relación deuda/PIB. En la medida en que este valor afecte directamente la solvencia, existe una relación entre la tendencia prevista del ingreso del país expresado en dólares y la evolución de la prima de riesgo-país. El abandono de la convertibilidad en diciembre de 2001 y la acentuada devaluación del peso que le siguió dejaron en claro que los ingresos en dólares serían muy inferiores a lo previsto.

\section{La duración de los contratos y la profundi- zación financiera}

Según la hipótesis relativa a la interacción de los factores microeconómicos y macroeconómicos, antes analizada, la modalidad de crecimiento intermitente (de "para y sigue") y el cambiante nivel de volatilidad deben haber inducido cambios permanentes en el 
comportamiento de los agentes y, por lo tanto, en el sistema económico. En este sentido, un efecto importante de la inestabilidad macroeconómica fue el de modificar aspectos claves de las condiciones pactadas en los contratos. Durante el largo período de gran inestabilidad que se inició en 1975 es posible detectar modificaciones significativas en la duración de los contratos, la moneda en que se expresan y sus características en materia de riesgo. Esto ha tenido repercusiones permanentes y no neutras en la economía, que son vitales para entender la situación actual.

En el caso de Argentina, es un hecho comprobado que las variaciones de la inflación y la volatilidad, así como los cambios en el sistema monetario, influyen en la duración de los contratos. Dicho en otras palabras, tras los brotes inflacionarios de 1975 y 1989, en los mercados de bienes, de trabajo y financiero los plazos de vigencia de los contratos se acortaron de manera general y permanente. Si bien los contratos tuvieron alguna duración mayor mientras se aplicó el sistema de convertibilidad, cuando la inflación era baja, el fenómeno de la contracción de los plazos ha demostrado ser muy persistente.

Parte de la información sobre la preferencia por contratos flexibles de corto plazo tiene que ver con estudios sobre la paridad del poder de compra. En el caso de los países desarrollados, la condición de paridad del poder de compra no rige en el corto plazo, pero parece aplicarse cuando ha habido un período de ajuste prolongado. Por falta de datos, no se sabe cuál es el comportamiento de los países en desarrollo en esta materia (Froot y Rogoff, 1995; Edwards y Savastano, 1999). En los casos de Argentina y Brasil —quizá porque en los países con experiencia inflacionaria la inercia de los precios tiende a ser menor- las desviaciones en torno a la media son de tamaño superior al de otras economías, pero la duración media de las desviaciones es menor. En realidad, la presencia de una raíz unitaria se rechaza más fácilmente en el caso del tipo de cambio real bilateral Argentina-Brasil, que en el de los tipos de cambio de los países desarrollados (Chudnovsky y Fanelli, 2001). En otras palabras, la experiencia histórica muestra que el tipo de cambio bilateral ha variado mucho, pero no parece acusar una tendencia "permanente", lo que indica que en situaciones de alta volatilidad los contratos son más cortos.

La relación entre la inestabilidad macroeconómica y la duración de los contratos también puede comprobarse examinando la intermediación financiera. Tras años de inflación muy elevada, en 1990 la relación en- tre M3 y el PIB se situó en torno al 5\% y los plazos de los créditos y depósitos fueron extremadamente cortos. El descenso de la inflación y de la volatilidad que se registró durante la vigencia del sistema de convertibilidad estimuló la profundización financiera y la mayor duración de los contratos, aunque el proceso fue lento. En 2000, tras nueve años de convertibilidad, 70\% de los activos de los bancos y $82 \%$ de sus obligaciones tenían plazos inferiores a 90 días. Pero en todo caso, estos fenómenos no tuvieron base firme. La crisis financiera actual está borrando totalmente los acontecimientos financieros positivos de los años noventa y, en la práctica, el breve plazo de los depósitos facilitó la corrida de los bancos.

A decir verdad, en Argentina la poca profundización financiera ha sido un problema permanente, al que han contribuido la inestabilidad macroeconómica y las reiteradas crisis financieras del país. La falta de desarrollo financiero es fuente de ineficiencia y un freno al crecimiento, ya que puede suceder que las empresas renuncien a realizar negocios rentables por no tener acceso expedito a los mercados de crédito y por las fallas de los mercados financieros. Además, cuando los reveses financieros son generalizados, las fluctuaciones macroeconómicas afectan la posición financiera de las empresas, dificultando el manejo del riesgo y de las consecuencias de las fases recesivas del ciclo económico.

Los resultados obtenidos por Fanelli, Bebczuk y Pradelli (2001) respaldan esta hipótesis. Estos autores recurrieron a datos de panel de sociedades anónimas argentinas y utilizaron el método $\mathrm{GMM}^{7}$ para estimar los efectos de las imperfecciones de los mercados financieros y las variables macroeconómicas sobre el proceso de inversión y la estructura de capital de la empresa. Para examinar la importancia de los desequilibrios macroeconómicos y la profundización fianciera utilizaron la prima de riesgo-país y la relación entre el crédito privado y el PIB, respectivamente. Estimaron dos ecuaciones para la estructura financiera en que las variables dependientes eran, respectivamente, la proporción de deuda de largo plazo y la proporción de deuda en dólares. Por lo que toca al desarrollo financiero, la hipótesis sostiene que en el decenio de 1990 la profundización financiera y la afluencia de capitales incrementaron la oferta de crédito, lo que permitió

\footnotetext{
${ }^{7}$ Generalized Method of Moments.
} 
que las empresas aumentaran su apalancamiento tras un largo período de racionamiento severo. Comprobaron que tanto la macroeconomía como la profundización financiera influyen en la composición de la deuda, en lo que se refiere a los plazos de los contratos y la moneda en que se expresan. Dicho en otras palabras, el coeficiente del riesgo-país es significativo y negativo (es decir, hay una relación inversa entre la proporción de la deuda que es de largo plazo o está expresada en dólares, y el riesgo-país), mientras que la influencia de la relación crédito/PIB es significativa y positiva. En estas dos regresiones de la estructura financiera, las variables que reflejan problemas de agencia y de información, como el tamaño de la empresa, y la tangibilidad, también tienen un efecto importante. En cuanto a la ecuación de inversión, los flujos de caja y el riesgo-país también son significativos. En suma, esto indica que las imperfecciones financieras influyen y que hay nexos directos entre las variables globales y las decisiones que se toman a nivel microeconómico.

La coexistencia de libre movilidad del capital y falta de profundización financiera puede ser fuente de incertidumbre macroeconómica y financiera, puesto que las corrientes internacionales de capital que fluyen hacia economías emergentes distan mucho de ser estables. Al mismo tiempo, las autoridades no cuentan con instrumentos suficientes para aminorar las consecuencias de cambios repentinos en la intensidad y orientación de los flujos. En Argentina, en la época de la convertibilidad y de libre movimiento del capital, había una estrecha relación entre los flujos de capital, la generación de crédito y el nivel de actividad. A fines de 1998, esta relación se tradujo en una dinámica macroeconómica perversa, que llevó finalmente a la cesación de pagos internos y externos.

Bajo el sistema de convertibilidad, las perturbaciones externas, tanto positivas como negativas, influían en el costo del crédito interno. Al respecto, el principal vínculo entre los mercados de crédito externos e internos era la prima del riesgo-país. Los cam- bios en las condiciones de los mercados de capital de países emergentes o en el panorama macroeconómico del país se reflejaban de inmediato en variaciones de la prima del riesgo-país. La volatilidad de las condiciones internas y externas repercutía así en el costo del crédito y en la demanda global. El gráfico 5 muestra la evolución de la prima del riesgo-país medida por el margen de Емв1 y la compara con la tasa de crecimiento trimestral de la economía. Ambas variables acusan alta volatilidad, y existe una relación marcada y negativa entre los cambios en la prima de riesgo-país y los cambios en la tasa de crecimiento trimestral del PIB.

Otro rasgo importante es la estrecha relación entre la oferta de crédito y el nivel de actividad. En rigor, dadas las imperfecciones del mercado de capitales, parece plausible que los cambios en la disponibilidad de crédito sí tengan importancia para el nivel de actividad. Utilizando un modelo de corrección de errores, Fanelli y Keifman (2002) obtuvieron resultados que coinciden con las hipótesis relativas a una asociación positiva importante en el corto plazo entre crédito y producción y de una relación inversa entre la prima de riesgo-país y la evolución de la macroeconomía.

GRAFICO 5

\section{Argentina: Riesgo-país y actividad económica}

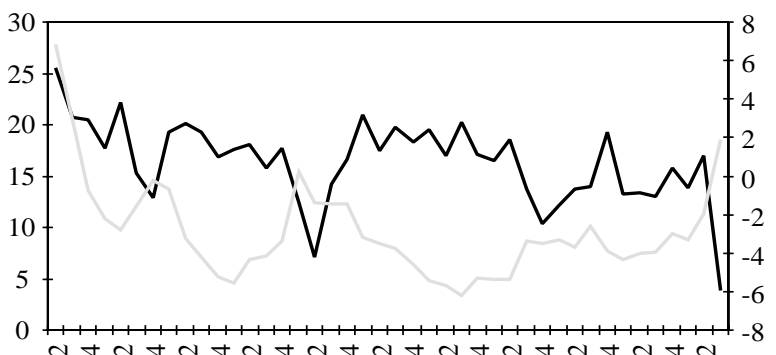
হু

Margen EMBI $\quad$ PIB Tasa de crecimiento del riesgo-país - ajustada por estacionariedad 


\section{III}

\section{Asimetrías, rigideces y efectos dinámicos como fuentes de inestabilidad}

Los países en desarrollo tienden a ser inestables, pero la evidencia analizada indica que Argentina es más volátil de lo que cabría prever a juzgar por su PIB per cápita. No tenemos elementos que nos permitan suponer de partida que las perturbaciones que afectan normalmente a la economía argentina sean de por sí más volátiles que las que afectan a países en desarrollo similares (aunque podemos aducir que la secuencia específica de las perturbaciones en 1998-1999 hizo que ese período fuera particularmente tenso). Esto significa que habría que buscar fuentes internas de inestabilidad. Los mejores candidatos son, por una parte, las características de la estructura económica (rigideces, asimetrías) que pueden amplificar los efectos de las perturbaciones y, por la otra, los efectos dinámicos y de retroalimentación que pueden apalancar perturbaciones como las fluctuaciones en la relación de intercambio, los impulsos fiscales o súbitas reversiones en los flujos de capital.

Aquí nos centraremos en dos temas. En primer lugar analizaremos una serie de aspectos estructurales que han contribuido en forma decisiva a amplificar las perturbaciones que precedieron a la caída del régimen de convertibilidad y a generar el actual estado de desorganización económica: i) las asimetrías de la integración argentina al comercio mundial y a los mercados financieros; ii) las restricciones impuestas por las rigideces nominales y fiscales y por las diferencias en la velocidad del ajuste de variables claves, y iii) la falta de desarrollo financiero y la dolarización. En segundo lugar, analizaremos la secuencia de perturbaciones de 1998-1999.

\section{La integración internacional asimétrica}

La integración de Argentina a la economía mundial exhibe dos asimetrías fundamentales entre lo real y lo financiero. Primero, pese a que el grado de apertura de la economía al comercio es poco, su apertura a los flujos de capital es mucho mayor. Segundo, las corrientes de comercio entre Argentina y los Estados Unidos son muy reducidas, pero el grueso de la deuda externa argentina se expresa en dólares y la intermediación financiera interna está en gran medida dolarizada. Otra asimetría que puede ser fuente de inestabilidad es aquella entre el elevado endeudamiento del sector público y el volumen importante de activos extranjeros que mantiene el sector privado.

El gráfico 6 muestra el grado de apertura de Argentina, de algunos otros países latinoamericanos y de la región en su conjunto. El coeficiente de apertura, medido por la relación entre las exportaciones y las importaciones y el PIB, es uno de los más bajos de América Latina. Esto se explica en parte porque el país aplicó durante mucho tiempo una estrategia de industrialización basada en la substitución de importaciones. Pero también es cierto que no tuvieron mucho más éxito las reformas estructurales del decenio de 1990 orientadas a abrir la economía, incluyendo la participación en un acuerdo regional como el Mercosur. Un hecho importante asociado a la baja apertura de Argentina es que las proporciones relativas de los factores de producción determinan que sus ventajas comparativas se encuentren en los "sectores equivocados". Las políticas agrícolas mercantilistas que se aplican en el mundo desarrollado limitan seriamente las posibilidades del país de explotar plenamente sus ventajas comparativas "naturales" en productos del agro. Otro fac-

GRAFICO 6

Apertura: América Latina, Argentina, Brasil, México y Chile (Exportaciones e importaciones como porcentaje del PIB, a precios de mercado)

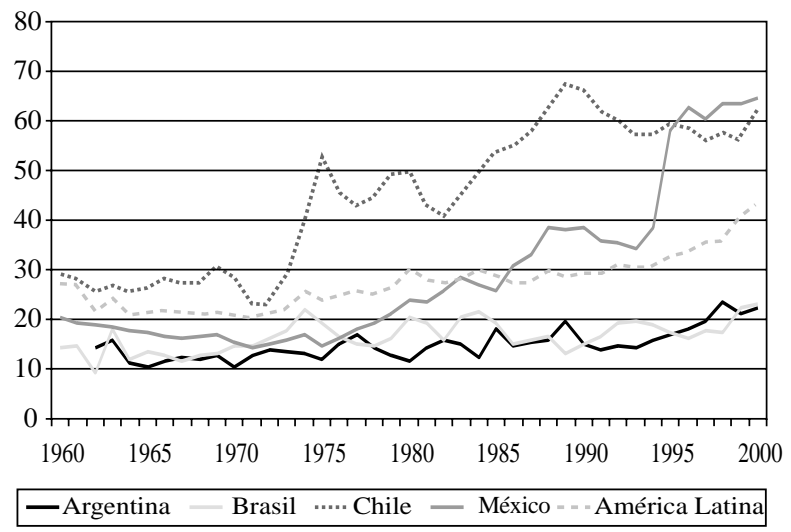


CUADRO 3

Argentina: Los flujos financieros en el decenio de 1990

(Porcentaje del PIB, promedios anuales)

\begin{tabular}{lccc}
\hline & $1991-1995$ & $1996-2000$ & $1990-2000$ \\
\hline $\begin{array}{l}\text { Inversión extranjera directa } \\
\text { Aumento de pasivos }\end{array}$ & 2.4 & 3.1 & 2.8 \\
$\quad$ en el extranjero & 3.6 & 4.2 & 3.9 \\
$\begin{array}{l}\text { Aumento de activos } \\
\quad \text { en el extranjero }\end{array}$ & 3.2 & 2.8 & 3.0 \\
$\quad \begin{array}{l}\text { Déficit en cuenta corriente } \\
\text { Acumulación de reservas }\end{array}$ & 2.5 & 3.9 & 3.0 \\
& 0.3 & 0.8 & 0.6 \\
\hline
\end{tabular}

Fuente: Elaboración propia basada en CEPAL (2002).

tor que conspira contra la apertura es que su vecino y socio más importante, Brasil, tiene una economía bastante cerrada, mientras que América Latina en su conjunto es también relativamente cerrada.

El panorama varía bastante si miramos los movimientos de capital en función de acervos y flujos. En el decenio de 1990, cuando el país tenía acceso a los mercados de capital, Argentina fue receptora privilegiada de inversión extranjera directa y de flujos de capital (cuadro 3). Reflejando el acceso al endeudamiento, la relación entre la deuda externa y el PIB es una de las más elevadas de la región. En cierto sentido, podría decirse que los países desarrollados se comportaron de manera irracional, porque otorgaron grandes créditos a un país cuyos productos no les interesaba comprar. Era de esperar que un país que confrontaba un alto nivel de proteccionismo tuviera dificultades para cumplir con sus obligaciones financieras.

Esta asimetría entre lo real y lo financiero es fuente de inestabilidad financiera porque la economía está muy apalancada en términos de bienes transables. $\mathrm{Si}$ se utiliza la relación deuda externa/exportaciones como una variable que refleja ese apalancamiento, resulta claro que en Argentina este último es excesivo. El cuadro 4 muestra las cifras correspondientes a Argentina, Brasil, Chile y México. Argentina exhibe la relación más alta, que tendió a elevarse en el decenio de 1990, pese a que el proceso de privatización ayudó a financiar el desequilibrio externo sin aumentar la deuda externa. Obsérvese, de paso, la evolución marcadamente positiva de este indicador en el caso de México, luego de la firma del Tratado de Libre Comercio de América del Norte. La integración regional con los Estados Unidos se tradujo en un coeficiente de apertura mucho más alto, y el Tratado también contribuyó a aumentar las corrientes de IED. De ahí que la deuda
CUADRO 4

América Latina (cuatro países): Relación deuda externa/exportaciones

\begin{tabular}{llllll}
\hline & 1980 & 1985 & 1990 & 1995 & 2000 \\
\hline Argentina & 3.4 & 5.9 & 5.1 & 4.7 & 5.5 \\
Brasil & 3.2 & 4.1 & 3.9 & 3.4 & 4.3 \\
Chile & 2.4 & 5.4 & 2.2 & 1.4 & 2.1 \\
México & 2.8 & 3.7 & 2.6 & 2.1 & 0.9 \\
\hline
\end{tabular}

Fuente: Datos de CEPAL (2002).

externa mexicana no aumentara después del "efecto tequila" y que el país pudiera financiar su déficit de cuenta corriente a partir de estos flujos de IED. Este resultado muestra una manera segura y sostenible de reducir la excesiva exposición al riesgo externo y la inestabilidad financiera.

En el decenio de 1990 el grado de integración de Argentina en los mercados de capital fue muy superior, pero esa integración fue extremadamente imperfecta. Una de sus características importantes fue la inestabilidad de los flujos, que se vieron afectados por el contagio y por interrupciones repentinas. La incidencia de estos factores fue decisiva cuando se hizo sentir el "efecto tequila" y después de la crisis rusa. Otro defecto de la integración argentina es que el país no mejoró mucho su capacidad de diversificar el riesgo nacional. Ya hemos señalado la elevada volatilidad del consumo global. Asimismo, Fanelli (2000) ofrece evidencia de la falta de correlación entre el consumo de Argentina y el consumo del mundo (representado por el consumo de los Estados Unidos).

Las dificultades para administrar el riesgo nacional crean un vínculo entre la incertidumbre macroeconómica y la demanda de divisas. En el caso de Argentina, las situaciones macroeconómicas "malas" generalmente se caracterizan por una marcada devaluación de la moneda y recesión. Así, las situaciones de consumo bajo se relacionan directamente con tipos de cambio real altos. De ahí que en un contexto en que los mercados son incompletos, los agentes utilicen activos extranjeros para protegerse de esta "mala" situación. De ello se desprende que será natural que se acreciente el deseo de cubrir posiciones abiertas en divisas cuando aumenta la incertidumbre "pura".

El papel de cobertura de riesgo que desempeñan los activos externos mantenidos por los residentes puede rastrearse en la balanza de pagos y en la posición financiera neta del país. Específicamente, la búsqueda de cobertura se refleja en el hecho de que el endeudamiento externo neto argentino es muy bajo. 
Tomada como un todo, Argentina no es un país muy endeudado: los activos que posee el sector privado en el extranjero representan alrededor de $75 \%$ del valor de la deuda externa, que en gran medida corresponde al gobierno. Esta relación entre el valor de los activos y pasivos es consistente con la evolución de la cuenta de capital de la balanza de pagos en el decenio de 1990. El cuadro 3 muestra que en ese período los flujos de activos y pasivos financieros fueron muy similares, lo que significa que los flujos de IED habrían bastado casi para financiar los desequilibrios de la cuenta corriente. Esto indica que en el "problema de la deuda" hay una dimensión puramente financiera, que está más relacionada con el deseo de protegerse del riesgo y del peligro moral (véase más adelante) que con la demanda de ahorro extranjero para financiar la inversión interna. En términos netos, el aumento de la deuda externa se utilizó para financiar la acumulación de activos financieros y no la inversión real. ${ }^{8}$

Este panorama de acervos y flujos parece contraponerse al que ofrece la actual crisis financiera. Una de las principales causas de la crisis fue la existencia de grandes colocaciones en divisas que no estaban efectivamente cubiertas. Aunque esto es verdad, hay que tener en cuenta varios factores. Primero, no fue el sector privado sino el gobierno el que estuvo más descubierto. Segundo, es posible que existiera un problema de riesgo moral. Muchas empresas que estaban muy endeudadas en dólares pueden haber supuesto que, en caso de una crisis generalizada tras el abandono de la caja de conversión, el gobierno "pesificaría" las obligaciones en dólares. Posteriormente se comprobó que estaban en lo cierto. Tercero, es posible que la gestión errada del riesgo haya tenido parte de la culpa. Más concretamente, quizá las autoridades bancarias no prestaron atención al fenómeno de migración de riesgos en virtud del cual el riesgo cambiario se convirtió en riesgo crediticio.

\section{Las rigideces y los efectos dinámicos y finan- cieros}

$\mathrm{Al}$ parecer, las economías abiertas son más inestables pero crecen más rápido (Easterly, Islam y Stiglitz, 2000). Sin embargo, la economía argentina es relativamente cerrada, crece poco y es volátil. A continuación, examinaremos brevemente algunas rigideces, así

\footnotetext{
${ }^{8}$ Nótese que lo mismo sucedió en Chile, país cuya política económica es mucho mejor que la de Argentina.
}

como posibles efectos dinámicos y financieros que pueden haber influido en esto y que desempeñaron un papel importante en el período de convertibilidad.

Por lo general, la imperfección del mercado que rompe la neutralidad e incorpora problemas monetarios en el análisis es cierta rigidez en el ajuste de los precios nominales. Cuando éstos son inflexibles, la política monetaria puede influir marcadamente no sólo en la demanda global sino también en el tipo de cambio real. ${ }^{9}$ Ya hemos dicho que las rigideces de los precios ciertamente contribuyen a explicar la elevada volatilidad del tipo de cambio real observado (véase el gráfico 2).

Sin embargo, Easterly, Islam y Stiglitz (2000) ponen de relieve dos aspectos a los que debería darse más protagonismo. El primero es el de las diferencias en la velocidad del ajuste y los efectos distributivos a que dan lugar las fluctuaciones de los precios que generan efectos contra los cuales las personas no pueden asegurarse con mercados incompletos. En estos casos, los efectos-ingreso pueden predominar sobre los efectos de sustitución originados en las variaciones de los precios. El segundo aspecto es el de los efectos dinámicos provocados por las restricciones que afectan al patrimonio y a los flujos de caja de las empresas y las instituciones.

En el caso argentino, los efectos-ingreso y financieros revisten importancia, lo que quedó particularmente de manifiesto en la interacción del ajuste fiscal, la recaudación tributaria y el nivel de actividad a partir de 1998. A comienzos de 2000, cuando ya había comenzado la recesión económica, el nuevo gobierno hizo grandes intentos por reducir el déficit fiscal. Las autoridades partieron de la base de que si se reducía el déficit se restablecería la confianza y los inversionistas extranjeros aportarían los recursos tan necesarios. Sin embargo, sucedió precisamente lo contrario. Los impuestos recaudados no aumentaron y la economía cayó en una recesión aún más profunda. Esta clase de efecto desestabilizador es característico de la economía argentina y obedece a la conjunción de fuertes efectos-ingreso con un comportamiento procíclico de los mercados de capital. Todos estarían de acuerdo en que no es muy acertado aumentar los impuestos en una fase recesiva y en que habría que evitar los efectos-ingreso que las alzas de impuestos inducen. Sin

\footnotetext{
${ }^{9}$ En la literatura relativa a los países desarrollados se supone que esta imperfección es la más importante desde el punto de vista empírico (Basu y Taylor, 1999; Taylor, 2000).
} 
embargo, para evitar el ajuste en un período de recesión el gobierno debería estar en condiciones de financiar el déficit, cosa que no ocurría en Argentina en el año 2000. Obviamente, la mejor solución es aplicar políticas fiscales prudentes. Por ejemplo, una de las principales fuentes del desequilibrio presupuestario fue la mal concebida reforma del sistema de seguridad social, que originó un déficit importante. También hay que mencionar los excesos cometidos durante el proceso electoral en el período 1998-1999. Al respecto, uno de los rasgos negativos del sistema de convertibilidad fue suponer que una caja de conversión impondría orden de inmediato en las cuentas del gobierno: éste no podría fabricar dinero y los mercados no otorgarían crédito a un gobierno que aplicara políticas fiscales débiles. Estos argumentos, sin embargo, descartaban la posibilidad de errores de expectativas por parte de los que participan en el mercado, lo que no parece prudente cuando la economía es volátil.

La preocupación por los balances de las empresas y las instituciones financieras se justifica en Argentina. Las condiciones crediticias pueden responder rápidamente a los cambios en las percepciones de los inversionistas, de ahí la importancia de la forma en que evolucionen la volatilidad y el riesgo nacional en general. La evidencia que ofrecen Fanelli, Bebczuk y Pradelli (2001) indica que cuando se deteriora el escenario macroeconómico, se produce a la vez un desplazamiento hacia la demanda de divisas y un incremento de la demanda de financiamiento de corto plazo. Esto indica que las fases de crecimiento negativo crean presiones en los mercados cambiario y financiero, tanto externos como internos. Cuando la perturbación macroeconómica exógena es lo suficientemente fuerte, la combinación de estos fenómenos puede desencadenar las denominadas "crisis gemelas", que es precisamente lo que ha ocurrido en Argentina.

Las perturbaciones negativas reducen el capital de las empresas, aumentando la probabilidad de que experimenten problemas financieros. Un ejercicio de regresión revela que si la prima de riesgo-país se eleva un punto porcentual, el valor de las empresas cuyas acciones se transan en la Bolsa de Comercio de Buenos Aires baja 2.2 puntos porcentuales (Fanelli, 2000). En estos casos, los acreedores reaccionan trasladando su demanda hacia activos que vencen a corto plazo, a fin de vigilar mejor el comportamiento de los deudores y debido a que, si hay incertidumbre, aumenta la prima de liquidez. Pero si se supone que la duración de los activos se mantiene relativamente constante a lo largo del ciclo, al acortarse el plazo de vencimiento de la deuda la situación financiera de las empresas empeora aún más y aumenta la probabilidad de incumplimiento. Para los acreedores, el incremento señalado equivale a un movimiento ascendente en el costo de incumplimiento financiero (si el costo se calcula como la probabilidad de incumplimiento multiplicada por el costo). En estas circunstancias, lo lógico es que los acreedores traten de acortar los vencimientos para vigilar mejor a los deudores e imponerles disciplina. $\mathrm{Si}$ este razonamiento es válido, en períodos de recesión hay factores endógenos que tienden a abreviar los plazos de vencimiento y aumentar la fragilidad financiera.

Lo anterior se relaciona estrechamente con el fenómeno de la migración del riesgo. En el sistema financiero, el riesgo tiende a trasladarse debido a que las operaciones de cobertura no reducen el riesgo sistémico. Sólo transfieren la exposición al riesgo o transforman el tipo de exposición. En el caso de Argentina, esto es muy importante. Cuando aumenta el riesgo sistémico percibido, los bancos se protegen contra el riesgo cambiario y tratan de equiparar los plazos de maduración de los activos y los pasivos. Como consecuencia, en las fases recesivas la liquidez de las empresas disminuye y sus obligaciones vencen en plazos más cortos. Esto acrecienta su vulnerabilidad, incrementanto así el riesgo para la contraparte. En definitiva, el intento de los bancos por cubrirse del riesgo se traduce en que éste deja de ser cambiario y se transforma en crediticio. Además, mientras más traten los bancos de mitigar el riesgo, mayores probabilidades hay de que las pérdidas imprevistas se trasladen rápidamente de un mercado a otro. A medida que el riesgo se traslada a través del sistema, tiende a emerger en su forma más elemental, como riesgo crediticio (Kimbal, 2000). Cuando se tiene en cuenta el fenómeno del traslado del riesgo y sus efectos en la solvencia de los bancos, el argumento de Calomiris y Powell (2000) sobre la disciplina del mercado se debilita. Para estos autores, la restricción de la oferta de crédito que se produce en las fases recesivas es señal de que el sistema financiero es vigoroso, porque en períodos de recesión y de grandes pérdidas por préstamos es precisamente lo que cabría esperar de un sistema bancario sometido a la disciplina del mercado. No obstante, el caso argentino sugiere que en el marco de un sistema económico en general débil, el sector financiero no se hace más saludable si se limita a trasladar el riesgo a las empresas, porque esto también le rebotará. 


\section{Perturbaciones simultáneas y fragilidad finan- ciera}

Ya hemos destacado las notables diferencias que exhibe el comportamiento económico de Argentina entre 1991-1998 y 1999-2000. El punto de quiebre puede situarse en el tercer trimestre de 1998, cuando se inició la prolongada recesión actual. Las diversas perturbaciones externas que sacudieron severamente a la economía en el período 1998-1999 fueron decisivas. Cualquiera de ellas habría bastado para provocar importantes desequilibrios macroeconómicos. Pero el hecho de que se produjeran al mismo tiempo agravó sus efectos y la economía no estaba preparada para absorber las consecuencias y manejarlas. Ya hemos identificado deficiencias de la estructura económica y mecanismos dinámicos que pueden haber agravado significativamente los efectos de las perturbaciones.

Otro factor que contribuyó a agravar la crisis y exacerbar la fragilidad financiera fue la mala calidad de las políticas económicas, en un marco de inestabilidad política. Los mecanismos anticíclicos a los que podían echar mano las autoridades eran bastante limitados y por ello es claro que Argentina hubiera experimentado una recesión importante en cualquier escenario posterior a 1998. Pero el hecho es que los mecanismos disponibles no se utilizaron eficientemente, en lo cual fue determinante la influencia de factores políticos. En el período preelectoral de 1998-1999 las autoridades aplicaron políticas fiscales contradictorias que se tradujeron en endeudamiento excesivo del sector público, complejas relaciones entre el gobierno federal y los gobiernos provinciales, desplazamiento financiero del sector privado y creciente tensión financiera. Las políticas que aplicó el gobierno políticamente débil que asumió el poder en diciembre de 1999 no corrigieron la situación.

La apreciación del dólar y la crisis financiera global del período 1998-1999 contribuyeron de manera decisiva a generar los desequilibrios, puesto que gatillaron diversos sucesos que tuvieron efectos adversos en la economía argentina (cuadro 5).

En el período de convertibilidad, la apreciación del dólar afectó directamente la competitividad de los exportadores argentinos, ya que la mayor parte de las exportaciones de Argentina no tiene por destino los Estados Unidos. Como el peso argentino tenía paridad fija con el dólar, un dólar fuerte significaba un peso sobrevaluado. Ese dólar fuerte tuvo otra consecuencia importante. En 1998 Brasil utilizaba el tipo de cambio nominal como mecanismo antiinflacionario y exis-
CUADRO 5

\section{Argentina: La crisis del período 1998-1999}

Deterioro de la relación de precios del intercambio (variación porcentual)

Caída del precio de las exportaciones

(variación porcentual)

Caída de las exportaciones a Brasil

(variación porcentual)

Devaluación del real brasileño respecto del peso argentino (Indice mundial de precios)

Aumento del valor del dólar

respecto del euro (porcentaje)

Salida neta de capital

(como porcentaje del PIB, excluida la IED)

Aumento de los pagos del sector público

por concepto de intereses (como porcentaje del PIB)

Fuente: Datos de la CEPAL.

tía una paridad relativamente fija entre el real y el dólar. En estas circunstancias, el mayor vigor del dólar aumentó las presiones sobre el tipo de cambio real de Brasil hasta que, finalmente, en enero de 1999, el país optó por un sistema de flotación. Con la marcada devaluación del real brasileño, a Argentina le resultó mucho más difícil competir con las exportaciones de su vecino. La situación se agravó por la caída de la demanda interna total en Brasil. En los dos años que siguieron a la devaluación del real, las exportaciones argentinas disminuyeron sustancialmente (cuadro 5). La asimetría entre el sentido de las corrientes comerciales (que fluían hacia Europa y el Mercosur) y los flujos financieros expresados en dólares también tuvo importancia. Como lo indica el cuadro, el deterioro de los términos de intercambio se acompañó de una caída del valor nominal de los precios de las exportaciones. A igualdad de otras condiciones, esto aumentó la carga de la deuda en relación con las exportaciones argentinas y deterioró el indicador deuda/exportaciones. Estos sucesos afectaron la solvencia argentina a tal punto que ella comenzó a ser objeto de un severo escrutinio.

Cuando se inició la crisis asiática, y particularmente después de lo sucedido en Rusia, los intereses que pagaba Argentina a sus acreedores extranjeros y nacionales experimentaron un marcado incremento. En el período 1998-1999 los pagos del gobierno por concepto de intereses se elevaron en un punto porcentual del PIB (cuadro 5). Pero esto no fue más que el comienzo, ya que en 2000 la carga de los intereses llegaría a $3.3 \%$ del PIB (a partir de 1.8\% en 1997). Además, la afluencia neta de capitales cayó más de un punto por- 
centual del PIB. El alza desmesurada de los intereses y las severas limitaciones de liquidez menoscabaron rápidamente la solvencia del país.

La deuda argentina medida en relación con el PIB no era alta. En 1997, la relación deuda/PIB de $43 \%$ concordaba con los estándares latinoamericanos. Otros países de la región en situación similar a la de Argentina no dejaron de cumplir sus compromisos externos. Sin embargo, en el caso argentino es preciso tener en cuenta el papel que desempeñaron algunos de los mecanismos estructurales desestabilizadores antes examinados, a saber, la elevada relación deuda/exportaciones, que aumentaba por la caída de las exportaciones, y el hecho de que los inversionistas puedan haber previsto que el valor del PIB en dólares, y por lo tanto los ingresos del gobierno, caerían en picada si se abandonaba el sistema de convertibilidad. En estas circunstancias, los desequilibrios macroeconómicos desencadenaron efectos de retroalimentación. A medida que aumentaba la probabilidad de devaluación, los que deseaban obtener préstamos tenían que ofrecer pagar intereses más altos para compensar a los otorgantes de crédito el mayor riesgo. Por su parte, el alza de las tasas de interés contribuyó a aumentar el riesgo de incumplimiento, lo que condujo a elevar aún más las tasas de interés, y así sucesivamente.

No obstante que esta dinámica empeoraba cada vez más la situación financiera de los bancos, al comienzo de la crisis el sistema bancario pudo hacer frente a las presiones. Después del efecto tequila, las reservas bancarias aumentaron sustancialmente y se aplicaron normas prudenciales más severas basadas en los acuerdos de Basilea, lo que se tradujo en una mayor capitalización de los bancos $(11.5 \%$ de los activos en riesgo). Sin embargo, cuando hay una recesión persistente en que los riesgos emigran y los contratos financieros tienden a ser de corto plazo, incluso activos bancarios de razonable calidad y liquidez pueden evolucionar muy desfavorablemente.

En 2001, mientras aumentaba sostenidamente la incertidumbre "pura" — en la medida en que lo hacía la probabilidad de que hubiera un cambio de sistema y se agravaba la recesión, deteriorando los activos bancarios - los depositantes se apresuraron a retirar sus depósitos. Ese año el total de los depósitos en el sistema financiero cayó $16 \%$. Esto generó crecientes problemas de liquidez, pese a un elevado coeficiente de reservas y a la vigorosa capitalización de los bancos privados a comienzos del año. El gráfico 7 muestra la evolución de los depósitos y el crédito durante la vigencia del sistema de convertibilidad.
GRAFICO 7

Argentina: Depósitos y créditos (Millones de pesos)

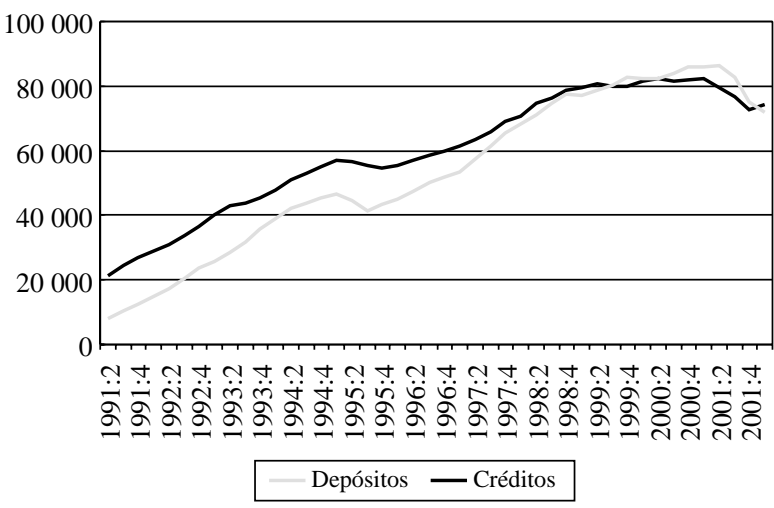

Otra consecuencia perturbadora de la profundización de los desequilibrios fue el persistente deterioro del equilibrio presupuestario. Hasta cierto punto, éste fue una consecuencia endógena de la caída de los ingresos del gobierno ocasionada por la recesión. A mediados de 2001, el severo racionamiento del crédito externo e interno obligó al gobierno a aplicar una política de "déficit cero", que pronto resultó un fracaso. A raíz de ello, el FMI se negó a desembolsar los fondos correspondientes a un acuerdo anterior. Dada esta situación, en enero de 2002 al gobierno no le quedó más remedio que caer en mora.

En diciembre de 2001, la situación de liquidez de varios bancos se hizo insostenible al acelerarse el retiro de los depósitos. Para detener esta sangría, el gobierno puso en práctica el llamado "corralito", en virtud del cual se prohibió retirar los depósitos del sistema bancario, aunque se permitía trasladarlos de un banco a otro. Pese a esta medida, la liquidez de los bancos sufrió una merma permanente "por goteo", ya que algunos depositantes encontraron formas legales de vencer la prohibición y el corralito admitía algunas excepciones (las llamadas cuentas salariales). Posteriormente, las restricciones se hicieron más estrictas a fin de refrenar la liquidez y detener la permanente depreciación del peso, pero las autoridades sólo tuvieron éxito parcial en sus propósitos.

Otra iniciativa clave para manejar la crisis fue la "pesificación" del crédito privado. Actualmente, el acervo de crédito privado en el sistema bancario se expresa en pesos y está parcialmente indizado con la inflación. La pesificación dio lugar a que se produjera una brecha importante entre el valor del activo y el pasivo de los bancos, lo que de hecho socavó totalmente el patrimonio neto de los bancos. En la actualidad, 
la situación se halla en una especie de punto muerto. Los bancos privados están exigiendo que se les pague indemnización por la pesificación. El gobierno piensa reemplazar los depósitos del corralito por bonos públicos y bancarios. En este contexto, la oferta de crédito ha desaparecido y resulta extremadamente difícil finan- ciar capital de giro, por no hablar de inversiones productivas. También hay enormes problemas para restablecer un sistema de pagos fluido. En suma, tras la aplicación del corralito y la adopción de un sistema de flotación, la economía tiene graves problemas financieros, fiscales e inflacionarios.

\section{IV}

\section{Observaciones finales}

A Argentina no le queda más remedio que hacer frente al futuro. Si se parte de la base de que las acciones del gobierno o del FMI no son totalmente inútiles para amortiguar los efectos de las perturbaciones y las crisis, debería concluirse que es posible concebir políticas nacionales más adecuadas y que para Argentina sería una gran ayuda que las organizaciones multilaterales se involucraran más a fondo. Mejorando las políticas se puede impedir que la capacidad productiva del país siga destruyéndose innecesariamente y que la población siga cayendo por debajo de la línea de pobreza.

Aunque a primera vista los obstáculos parecerían insuperables, basándonos en nuestro análisis podemos ofrecer algunas conjeturas acerca de la secuencia de políticas que debería aplicar el país para restablecer la estabilidad macroeconómica y financiera. Aquí examinaremos cuatro pasos que pueden darse con este propósito.

La aplicación del corralito, la mora en el pago de la deuda y la devaluación del peso dieron lugar a un incumplimiento general de los contratos y a la violación del derecho de propiedad. Unido a la aceleración inflacionaria y al cambio brusco de los precios relativos, este hecho exacerbó la incertidumbre pura. Dada la vinculación entre la incertidumbre y la demanda de activos extranjeros, antes examinada, estos acontecimientos han estado empujando la demanda de divisas hacia la derecha, lo que se tradujo en una combinación de pérdidas reiteradas de reservas y alzas exageradas del tipo de cambio. En estas circunstancias, las autoridades encaran el dilema de dejar que la inflación se dispare o permitir que las reservas caigan a cero. ${ }^{10}$

${ }^{10}$ Hay un círculo vicioso entre la fragilidad financiera de los bancos, el desequilibrio presupuestario, la inflación y la depreciación.
El primer paso, por lo tanto, es combatir la incertidumbre que constituye la raíz de este dilema. Para reducir la incertidumbre es fundamental restablecer y reforzar la infraestructura institucional y contractual que se desmoronó tras el fin de la caja de conversión. Con derechos de propiedad que no están claramente definidos, los agentes privados perciben que no tiene sentido esforzarse, ya que no está claro a quién corresponderán las futuras utilidades de los activos. Así pues, para que el nivel de actividad se recupere es fundamental que exista un mínimo de orden institucional. Y no estamos exagerando. El sistema financiero argentino es un caos. Nadie sabe cuál es el valor de los activos y pasivos de los bancos. Tras el cambio repentino de los precios relativos, es preciso renegociar los contratos de las empresas recién privatizadas que proporcionan servicios básicos como los de agua, energía y comunicaciones, algunas de las cuales han dejado de servir su deuda. El gobierno también está en mora en el servicio de su deuda externa, y otro tanto le sucede a buena parte de los agentes privados. Además, actualmente se está modificando la ley de quiebras. Todo esto indica que la construcción de instituciones y la transparencia son elementos esenciales de toda política económica coherente.

No hay duda alguna de que para reconstruir las instituciones hay que comenzar por el sistema financiero. Para evitar la hiperinflación, es preciso que el Banco Central deje de ayudar al sistema bancario. Por su parte, el sistema bancario es una pieza fundamental

Si el gobierno ayuda a los bancos mediante redescuentos o emite dinero para financiar el déficit, está aumentando la base monetaria y alimentando la demanda de divisas. Si deja que el tipo de cambio nominal se ajuste, la inflación se acelera. Si el Banco Central vende divisas para enfrentar el aumento de la demanda, las reservas pronto se agotan. 
para restablecer el sistema de pagos, financiar capital de giro y avanzar hacia una definición más precisa de los derechos de propiedad. Sin embargo, el sistema bancario reestructurado no podrá generar una oferta de crédito sustancial, pues tendrá escaso margen de acción. Esto significa que Argentina tendrá que desarrollar otros segmentos del mercado de capitales. Con todo, en la situación actual lo primero que hay que hacer es restablecer la capacidad del sistema bancario de prestar servicios básicos vinculados con las transacciones y el capital de giro.

Desde el punto de vista político, reestructurar el sistema bancario argentino no es tarea fácil. En las actuales circunstancias, el gobierno no puede asumir plenamente el costo de la crisis financiera, como lo hizo en oportunidades anteriores. Por lo tanto, para resolver la crisis hay que cumplir con dos requisitos indispensables. Primero, el costo de la reestructuración debe ser compartido por los contribuyentes, las firmas deudoras, los bancos y los depositantes. Segundo, es preciso obtener algún apoyo externo explícito y activo, ya que sin ese apoyo la precaria situación financiera del sector público no le permitirá llevar a cabo una reestructuración dotada de credibilidad.

Si el gobierno logra eliminar el corralito y al mismo tiempo evitar la hiperinflación, lo más probable es que se estabilicen tanto el tipo de cambio nominal como el nivel de actividad. Si esto se materializa, tal vez sea posible dar un segundo paso: centrarse en la estabilización de los ingresos del sector público y negociar un nuevo acuerdo con las provincias.

El tercer paso hacia la estabilización debería ser el de consolidar un régimen monetario y cambiario más sólido. Esto es fundamental para restablecer la capacidad de contratar. El sistema económico necesita un patrón nominal para denominar los contratos. Cuando la demanda de activos internos es inestable, parece razonable centrarse en estabilizar la inflación. ${ }^{11} \mathrm{En}$ todo caso, si el país evita la dolarización, en el futuro próximo el "régimen monetario" se caracterizará por un manejo relativamente "sucio" del tipo de cambio, probablemente con controles de capital incluidos.

Una de las principales metas de política debería ser la de evitar que se cometan "grandes" errores en el manejo del tipo de cambio o en el diseño del sistema cambiario. Al respecto, Argentina debería fijarse objetivos modestos pero firmes: el país debería evitar

${ }^{11}$ En Fanelli y Heymann (2002) examinamos detenidamente esta cuestión. políticas económicas que combinen un sistema cambiario rígido, endeudamiento externo excesivo y fallas fiscales, como sucedió con "la tablita" y la convertibilidad. Tales políticas permiten que por un tiempo el país se aproxime al PIB per cápita del "primer mundo" y reduzca artificialmente la volatilidad, pero sólo a expensas de un valor en dólares inflado de la producción de bienes no transables. Ya vimos que tarde o temprano los agentes económicos revisan sus expectativas y recalculan sus ingresos permanentes sobre bases más sólidas, y como resultado la economía se desmorona. A nuestro juicio, Argentina no debería llevar a cabo una dolarización total. La dolarización total probablemente conduciría a problemas como los que planteó la caja de conversión (Fanelli y Heymann, 2002).

Otra meta importante debería ser la aplicación de políticas de estabilización macroeconómica de "largo plazo", esto es, políticas que procuren transformar la estructura económica de manera de eliminar los elementos y desactivar los mecanismos que hacen que la economía sea volátil. En este trabajo hemos ilustrado largamente el hecho de que en Argentina la volatilidad y los cambios estructurales tienen importancia, y mucha. En realidad, dado que el país se caracteriza por la interacción perversa del crecimiento y la inestabilidad, uno de los elementos fundamentales de una política de crecimiento sustentable debería ser la creación de estabilizadores macroeconómicos.

El cuarto paso para estabilizar la economía es llegar a un acuerdo con los acreedores extranjeros. Pero este paso no puede darse antes que los otros tres. Sería difícil negociar con un gobierno que no puede recaudar impuestos ni garantizar instituciones económicas fundamentales como son el derecho de propiedad y los contratos. Dicho esto, está claro que Argentina tiene que resolver cuanto antes el problema de la deuda. La alternativa al endeudamiento excesivo, no es tener deuda cero. El país necesita acceder a los mercados internacionales de capital. Hemos visto que, además de la necesidad de ahorro externo, hay motivos relacionados con la diversificación. Al respecto, Argentina tiene mucho que aprender del pragmatismo chileno.

¿Y qué hay del crecimiento? ¿Existen recursos "ocultos" que podrían movilizarse para restablecerlo? Concluimos este trabajo con algunas conjeturas sobre el tema. En primer lugar, hay unos recursos - no tan ocultos- de los que Argentina está razonablemente bien dotada: los recursos humanos y naturales. Para impedir que este capital siga deteriorándose, es fundamental resolver la crisis y, al mismo tiempo, implementar 
políticas para movilizar los recursos. Al respecto, Argentina debería aprovechar al máximo el actual aumento de los precios relativos de los bienes transables y complementar esta acción con políticas vigorosas destinadas a mejorar los aspectos de la competitividad que no están relacionados con los precios y a abrir nuevos mercados.

Los países desarrollados que en el decenio de 1990 realizaron inversiones en Argentina y que últimamente han visto caer en picada el valor de sus bonos y de sus activos físicos, podrían ayudar mucho tanto al país como a la recuperación del valor de sus propias inversiones. Como parte de un conjunto de medidas de emergencia, podrían aminorar el proteccionismo comercial en determinados sectores para que Argentina pueda acceder a los mercados pertinentes. $\mathrm{Al}$ respecto, el país podría ofrecer una amortización más rápida de la deuda a cambio del acceso a los mercados. A la larga, no sólo se beneficiarían los argentinos sino también los consumidores e inversionistas de los países del Grupo de los 7. Argentina tiene la caña y sabe pescar. El problema es cómo comprar el pasaje para llegar al mercado de pescado. La experiencia mexicana es muy importante en esta materia. Después de que México ingresó al Acuerdo de Libre Comercio de América del Norte, los indicadores externos mexicanos mejoraron apreciablemente, gracias al aumento de las exportaciones y la inversión extranjera directa.
En segundo lugar, otros recursos ocultos son los activos que posee el sector privado en el extranjero. En gran medida, la acumulación acelerada de estos activos que se registró en los últimos años fue la contrapartida de una creciente incertidumbre económica. Al tipo de cambio actual, el acervo de recursos financieros que está en manos del sector privado es considerable y representa aproximadamente el $100 \%$ del PIB corriente. La devaluación real del peso tiene que haber tenido un importante efecto positivo en el patrimonio de una parte del sector privado. Tan pronto se estabilice la economía, este efecto patrimonial puede llegar a ser un poderoso incentivo de la demanda real. Además, hay que tener presente que, después de una recesión prolongada, seguramente aumentará la demanda de los bienes de capital y los bienes de consumo duraderos que se depreciaron en el período recesivo. Asimismo, el hecho de que las empresas tengan activos financieros líquidos significa que podrían financiar proyectos de inversión con recursos propios.

En tercer lugar, otro recurso que se puede movilizar es el Mercosur. Este acuerdo puede suministrar muchos de los insumos que Argentina necesita para sustentar su crecimiento: mercados nuevos para las exportaciones, la afluencia de inversión extranjera directa, y mercados de capital más profundos y activos a nivel regional. ${ }^{12}$

(Traducido del inglés)
Agénor, P., J. McDermott y E. Prasad (2000): Macroeconomic fluctuations in developing countries: Some stylized facts, The World Bank Economic Review, vol. 14, N², Washington, D.C., Banco Mundial.

Banco Mundial (1999): World Development Indicators 1999, Washington, D.C.

Basu, S. y A. Taylor (1999): Business cycles in international historical perspective, The Journal of Economic Perspectives, vol. 13, $\mathrm{N}^{\circ}$ 2, Nashville, Tennessee, American Economic Association.

BID (Banco Interamericano de Desarrollo) (1995): Progreso económico y social en América Latina. Informe 1995, Washington, D.C., octubre.

Calomiris, C. W. y A. Powell (2000): Can Emerging Market Bank Regulators Establish Credible Discipline? The Case of Argentina, 1992-1999, NBER working papers series, $\mathrm{N}^{\circ} 7715$, Cambridge, Massachusetts, National Bureau of Economic Research.

CEPAL (Comisión Económica para América Latina y el Caribe) (1998): CEPAL, Cincuenta años. Reflexiones sobre América Latina y el Caribe, Revista de la CEPAL, número extraordinario, LC/G.2037-P, Santiago de Chile.

(1999): Estudio económico de América Latina 1998-1999, LC/G.2056, Santiago de Chile.
(2002): Indicadores macroeconómicos de la Argentina, Buenos Aires, Oficina de la CEPAL en Buenos Aires.

Chudnovsky, D. y J. M. Fanelli (2001): El desafío de integrarse para crecer. Balance de una década de Mercosur, Madrid, Siglo XXI Editores.

Easterly, W., R. Islam y J. E. Stiglitz (2000): Shaken and Stirred: Explaining Growth Volatility, Washington, D.C., Banco Mundial.

Edwards, S. y M. A. Savastano (1999): Exchange Rates in Emerging Economies: What Do We Need to Know?, NBER working papers, $\mathrm{N}^{\circ} 7228$, Cambridge, Massachusetts, National Bureau of Economic Research.

Enders, W. (1995): Applied Econometric Time Series, Londres, John Wiley \& Sons.

Fanelli, J. M. (2000): Macroeconomic regimes, growth and the international agenda in Latin America, Latin American Trade Network Meeting, Buenos Aires, Facultad Latinoamericana de Ciencias Sociales (FLACSO), 8-9 de noviembre.

\footnotetext{
${ }^{12}$ En Chudnovsky y Fanelli (2001) analizamos el potencial de crecimiento del Mercosur.
} 
Fanelli, J. M., R. Bebczuk y J. Pradelli (2001): Determinants and Consequences of Financial Constraints Facing Firms in Argentina, Buenos Aires, Asociación Argentina de Economía Política, www.aaep.org.ar.

Fanelli, J. M. y D. Heymann (2002): Monetary dilemmas: Argentina in Mercosur, documento preparado para la International Conference Towards Regional Currency Areas, Santiago de Chile, CEPAL, marzo.

Fanelli, J. M. y S. Keifman (2002): Finance and changing trade patterns in developing countries, en J. M. Fanelli y R. Medhora (eds.), Finance and Competitiveness in Developing Countries, Londres, Routledge.

Fanelli, J. M. y M. Rozada (1998): Convertibilidad, volatilidad y estabilidad macroeconómica en Argentina, Estudios de política económica y finanzas. Revista de la Universidad de Palermo, año 5, $\mathrm{N}^{\circ}$ 2, Buenos Aires, Universidad de Palermo.
Froot, K. y K. Rogoff (1995): Perspectives on PPP and long-run real exchange rates, en G. Grossman y K. Rogoff (eds.), Handbook of International Economics, vol. III, cap. 32, Amsterdam, Países Bajos, Elsevier Science B.V.

Heymann, D., M. Kaufman y P. Sanguinetti (2001): Learning about trends: Spending and credit fluctuations in open economies, en A. Leijonhufvud (ed.), Monetary Theory as a Basis for Monetary Policy, Londres, Macmillan.

Kimbal, R. (2000): Failures in risk management, New England Economic Review, Boston, Federal Reserve Bank of Boston, enero-febrero.

Taylor, A. M. (2000): A Century of Purchasing Power Parity, NBER working papers series, $\mathrm{N}^{\circ} 7577$, Cambridge, Massachusetts, National Bureau of Economic Research. 